\title{
Current Status and Analysis on Space Service in East China Public Libraries: A Case Study
}

\author{
Qianqian Si, Jiayin Liu \\ Library, Nanjing University of Aeronautics and Astronautics, Nanjing, China \\ Email: siqianqian@shcac.edu.cn
}

How to cite this paper: $\mathrm{Si}, \mathrm{Q} . \mathrm{Q}$. and Liu, J.Y. (2019) Current Status and Analysis on Space Service in East China Public Libraries: A Case Study. Intelligent Information Management, 11, 77-86.

https://doi.org/10.4236/iim.2019.115007

Received: August 16, 2019

Accepted: September 15, 2019

Published: September 18, 2019

Copyright $\odot 2019$ by author(s) and Scientific Research Publishing Inc. This work is licensed under the Creative Commons Attribution International License (CC BY 4.0).

http://creativecommons.org/licenses/by/4.0/

\begin{abstract}
This paper provides references for the space service of public libraries in China. 51 public libraries in East China were investigated in terms of space type, space facilities and space service reconstruction; the current situation of space service was analyzed and some problems were revealed. Based on the investigation, the characteristics of public libraries' space service in East China are summarized from the perspective of space type, space service concept and space service mode. And the problems in the aspects of new space service level, space service facility construction and space service evaluation mechanism are pointed out. Through the analysis, space service strategies of public libraries in China are proposed: libraries' overall quality should be strengthened; space service based on information technology should be promoted; users' needs should be respected and evaluation mechanism should be developed.
\end{abstract}

\section{Keywords}

Public Libraries, Space Service, Space Type, Space Reconstruction, East China

\section{Introduction}

In the 21st century, with the rapid development of digital technology, great changes have taken place in the way readers obtain information and the borrowing rate of paper documents in libraries has decreased each year. Facing the double challenges from readers and external environment, the existing space services and space layout of libraries can no longer satisfy the demand of users. In recent years, the discussion and research on library space have become a new trend. In 2009, the International Federation of Library Associations and Institutions (IFLA), 
held in Turin, Italy, first linked libraries with the third space and put forward the concept of "space service". Since 2012, study on library space by domestic scholars has started. "Space re-engineering" was ranked the third by Wu Jianzhong in "Ten Hot Topics of Re-discussion on Library Development" [1]. Professor Ke Ping pointed out that "space and resource are two hot spots in future library design" at the "Symposium on Library Space Reconstruction and Functional Re-engineering" held in December 2018. Thus, "Library Space Service", as an important innovative mode under the transformation of libraries in the new century, has been a hot topic in the field of library research.

There is no consistent definition of "space service". Some scholars put forward the concept of "Space as Service". Physical library space has been transformed from a carrier of library service to one of the core library services [2]. Xiao Long of Peking University believes that differing from traditional library featured by collecting books and related services around collecting books, the newly added space is only for service, such as creative space, learning space, communication space and leisure space aiming to provide readers with cultural places for study, research and communication. It can be considered as "space service" [3].

In existing research, scholars have studied the space service of library from different angles. In terms of space layout, Zhang Wenliang believes that public libraries should actively carry out new space transformation, construct virtual information space and balance the proportion of traditional space and new space [4]. In terms of space service mode, Ma Chunhua discussed the service mode of maker space in academy library in the transition period, strengthened the design of entity space in libraries, equipped with reasonable tools and professional librarians [5]. Chen Jie discussed the mobile maker space service of the library, and pointed out that according to the characteristics of the library, the most suitable construction mode of mobile maker space should be selected, the operating system of maker space should be improved, the steady development of mobile maker should be promoted, and the online and offline experience channels should be established to meet user's individualized demand [6]. In terms of space service facilities, Dong Guangqin believes that libraries should improve readers' experience and promote interactive learning with perfect digital function facilities [7].

The above researches focus on a certain aspect of space service, and this paper tries to elaborate the current situation of space service of public libraries in East China from the perspectives of space type, space facilities and space service reconstruction. Besides, the characteristics and shortcomings of space services of public libraries in East China are summarized and improved space service strategies are put forward to provide a reference for the space service of public libraries in China.

This survey used the network survey. Considering that the number of public libraries in East China ranks first in all regions of the country, and the number of public libraries carrying out space service reconstruction is relatively large, 
therefore, the research objects were public libraries of East China. Investigation is carried out through direct access to public libraries' websites and searching target library by search engines. Among the 51 public libraries in East China, there are 24 libraries involved in the reconstruction of library space services with 11 libraries involved in two or more items, which are representatives in space service of public libraries in China.

The main body of this paper includes Section 2, Section 3 and Section 4. The second section mainly introduces the new space and traditional space, service facilities and service system as well as the space service reconstruction of public libraries in East China. The third section summarizes the characteristics and shortcomings of space service of public libraries in East China. Based on the second and third sections, it puts forward the space service strategy of public libraries in East China.

\section{Current Situation of Space Service of Public Libraries in East China}

\subsection{Space Types}

According to the space function, library space can be divided into traditional library space and new library space, which have different space function and different space service. In this paper, the space of 51 public libraries in east China is divided into two categories: the traditional space and the new space. Traditional spaces include reading, borrowing, office areas and special population spaces, while new spaces include entertainment $\&$ display spaces, educational spaces and Internet \& mobile areas. By investigating 51 public libraries' websites, 24 representative public libraries in space service were selected. These 24 public libraries have various functions in space areas. According to the classification proportion of space types, there are obvious differences in space types of public libraries in East China. Figure 1 is present to show the space setting of the 24 public libraries in East China.

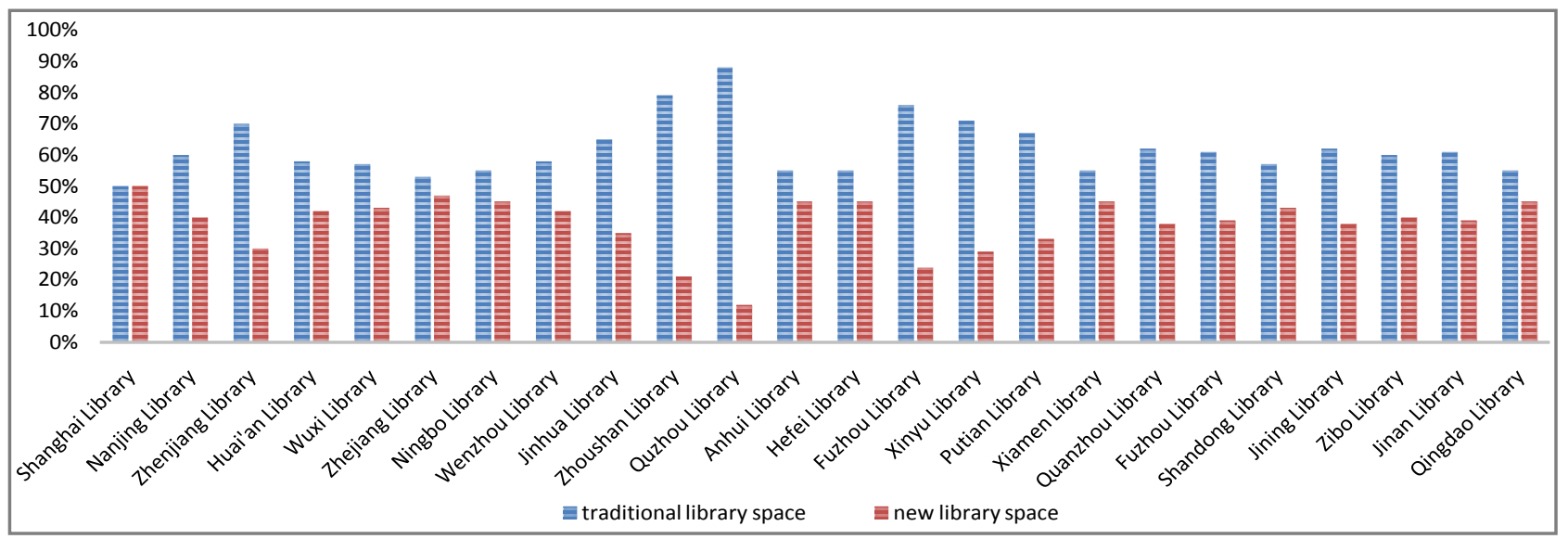

Figure 1. The space setting of the 24 public libraries in East China. 


\subsubsection{Traditional Library Space}

The space design of traditional libraries is centered on traditional service carriers (such as books, periodicals, newspapers, etc.) and the storage, lending and reading services take up a lot of space.

1) Reading, borrowing and office areas

Public libraries are cultural institutions open to the general public, and physical space is necessary to meet public's information needs. The office area covers the basic functional departments of the library. It is the physical space for librarians to finish their daily work. All the 51 public libraries surveyed in this paper have set up these three kinds of spaces. In terms of reading space, most public libraries take the area, environment and furniture of the reading area into consideration when designing new libraries. In terms of borrowing areas, most libraries provide Chinese and foreign language borrowing areas. Ancient books are usually only for reading in the library. In order to expand the scope of reading and borrowing, bookstores were opened in Shanghai library and Nanjing library. In terms of office area, the layout of office area is adjusted according to reader's needs. An integrated service area was set up on the first-floor lobby by Nanjing Library to provide centralized services for readers.

2) Special population areas (children, the elderly, the visually impaired)

The space needs of children, the elderly, and the visually impaired are different from those of the general public. Therefore, these groups were studied as a special population. Among the 51 public libraries surveyed, 45 public libraries have children's reading areas, accounting for $88 \%$ of the total. Jinan Library has set up children's digital reading experience areas in its new library. Only six public libraries have reading areas for the elderly, accounting for $12 \%$ of the total. 39 public libraries have reading areas for the visually impaired, accounting for $76 \%$ of the total. Figure 2 shows statistics on the number of libraries space for special population. Shandong Library has built digital reading rooms for the visually impaired, and Ningbo Library has set up multifunctional reading rooms for the

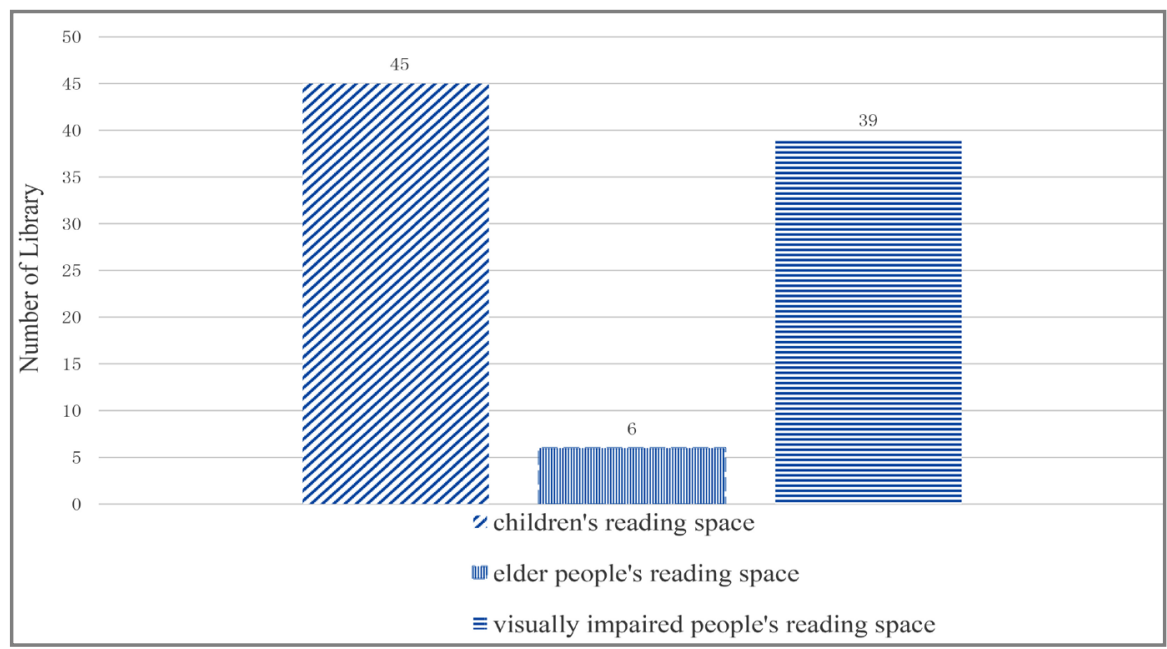

Figure 2. Statistics on the number of libraries space for special population. 
blind. Fuzhou Library has a nursing room and Shandong Library specially sets up a cultural center for migrant workers. Qingdao Library and Qingdao Massage Rehabilitation Hospital jointly established the first "Visually Impaired Book Flow Space", which broadened the service object and scope of public libraries in space.

\subsubsection{New Library Space}

The new library space, based on information technology and innovative service concept, is a new type of library space, such as learning space, creative space, leisure space and experience space [8]. It is a new type of library space for traditional libraries and a positive extension of the concept of space creation.

\section{1) Entertainment and display space}

Entertainment space is the third space created by public libraries for readers. Display space is a place where public libraries display objects for readers to appreciate. Both spaces can cultivate readers' sentiment and relax readers. The survey results show that 19 public libraries have set up distinctive entertainment spaces, mainly in the form of music halls, cafes, film halls, leisure book bars, etc. Ningbo Library and Qingdao Library have established music halls; Hefei Library, Jinhua Library and Wenzhou Library have set up leisure book bars; Shanghai Library and Xinyu Library have set up coffee bars; Huai'an Library and Xiamen Library have set up film halls. Apart from five public libraries, other libraries have set up exhibition areas with rich exhibition resources and distinctive features. Off-line physical exhibitions and online exhibitions are synchronized to ensure the full utilization of resources. Zhoushan Library promotes Marine knowledge to citizens with the help of its rich marine culture collection.

\section{2) Educational space}

Developing social education is one of the important functions of public libraries. It undertakes the task of educating ordinary citizens on scientific knowledge and culture. It is the base of continuing education and lifelong education for citizens. The definition of educational space in this paper includes civic schools, lecture halls, training classrooms and other cultural spaces with educational functions. According to the survey, all 51 public libraries have educational spaces, which differ in space names, but all have educational functions. Nanjing Library and Shandong Library have respectively set up national studies center; Jinhua Library has set up the public welfare classroom training course; Quzhou City library has set up the Confucianism training area; Fuzhou library and Ningbo Library have set up the special research room of readers.

\section{3) Electronic reading area and mobile service space}

With the development of Internet, the electronic reading area and mobile area of public libraries emerge as the times require. Digital resources access and mobile network information services are provided in library. Electronic reading area and mobile service space, which are complementary to traditional reading space, provide readers with a new reading space and expanding collection resources. All 51 public libraries surveyed in this paper have set up electronic read- 
ing area and mobile service space. Nanjing Library has transformed the electronic reading square to create green and comfortable electronic reading space for readers. The forms of mobile platform services provided by public libraries investigated in this paper include mobile APP, hand-held library, mobile library, WeChat subscription number, microblog platform, SMS self-service, etc. The service contents include book borrowing inquiry, news trends in the library, new book recommendation, resource retrieval, etc. Wuxi Library promotes the deep integration of "Internet+" and library, opens the Alipay credit borrowing card, and launches online borrowing and book delivery services on Alipay and WeChat platforms.

\subsection{Construction of Space Service Facilities}

The public libraries space service facilities provide a guarantee for readers to use library resources conveniently, help readers to better experience and use library resources from multiple perspectives.

\section{Self-service equipment and system}

The emergence of self-service equipment and system is the embodiment of "human-oriented" service concept of public library, which has positive significance for improving service efficiency, saving personnel cost, promoting readers' sense of participation and convenient service for readers. In terms of self-service equipment, the survey shows that the types of space service facilities in 51 public libraries mainly include 24-hour self-service equipment, e-book borrowing machine, electronic press machine, touch screen reading system, reading pavilion, big data service platform, self-service book sterilization machine and intelligent audio-book for visually impaired people. Most public libraries are equipped with 24-hour self-service equipment. Zhejiang Library provides intelligent listeners and novel German music seats for visually impaired readers. Wuxi Library is equipped with intelligent book delivery cabinet. Jining Library has built the first TV library in the province. In terms of self-service system, the survey shows that the self-service system of public library covers online self-service payment, self-service card application, self-service book ordering, RFID radio-frequency technology book positioning system, big data service platform system and so on. Big data service platform has been introduced into Wuxi Library to display daily library attendance, book borrowing and returning data, service stars, new book recommendation and other contents. The self-study room of Nanjing Library has opened WeChat service of "online seat selection".

\subsection{Space Service Reconstruction}

The survey shows that 24 public libraries have completed part of the space reconstruction in libraries. This paper takes 3 representative libraries as examples to discuss. The types of space reconstruction include spare space and functional reorganization space. As shown in Table 1, Nanjing Library reintegrates the functions of the service desk on the first floor to create an integrated service area. 
Table 1. Reconstruction of some public libraries space services.

\begin{tabular}{|c|c|c|c|c|}
\hline Library Name & $\begin{array}{l}\text { Reconstruction } \\
\text { area }\end{array}$ & $\begin{array}{l}\text { Reconstruction } \\
\text { reason }\end{array}$ & Reconstruction goal & Progress \\
\hline \multirow{2}{*}{ Nanjing Library } & $\begin{array}{l}\text { Service area on } \\
\text { first floor }\end{array}$ & $\begin{array}{c}\text { The service area is } \\
\text { decentralized }\end{array}$ & Integrated service area & Completed \\
\hline & Children's Library & Single function & $\begin{array}{l}\text { Integrated children's } \\
\text { service area }\end{array}$ & Completed \\
\hline Hefei Library & $\begin{array}{c}\text { Electronic reading } \\
\text { area }\end{array}$ & $\begin{array}{l}\text { Single function } \\
\text { and low utilization }\end{array}$ & Learning common area & Completed \\
\hline Qingdao Library & $\begin{array}{c}\text { 24-hour } \\
\text { self-service area }\end{array}$ & $\begin{array}{c}\text { Single function } \\
\text { and low utilization }\end{array}$ & Learning common area & Completed \\
\hline
\end{tabular}

Besides, in order to improve the utilization of space, Nanjing Library has added a recommendation reading desk in the spare space on the first floor. Hefei Library has transformed the e-reading area, not only upgrading the original electronic equipment, but also replacing the supporting furniture. The transformed space is a shared space for learning, experience and entertainment. Qingdao Library has renovated and upgraded the 24-hour self-service library, which not only expands the books, but also increases the salon area, reading area and leisure area.

\section{Summary of the Current Situation of Public Libraries Space Service in East China}

Based on the above investigation and analysis, the characteristics of public libraries space service in East China can be summarized from the perspectives of space type, space service concept and space service mode, and the problems in the aspects of new space service level, space service facility construction and space service evaluation mechanism are pointed out.

\subsection{Characteristics of Space Services}

Firstly, space types are abundant. The 51 public libraries surveyed have set up spaces with different functions for readers, such as coffee book bar, music library, national studies center, woman's reading space, maker space, exhibition hall and study room, etc. In addition, some public libraries are committed to developing characteristic service spaces. For example, Ningbo Library has built a characteristic music space for the public to appreciate and study music.

Secondly, the space service is diversified. The public libraries surveyed in this paper provide space services in various ways including optimizing and reorganizing spare space, creating characteristic service space, connecting physical space and virtual equipment, and jointly building with external forces, etc., and create a number of unique spaces, such as readers' comprehensive service area, military reading room, urban study, intelligent book room, forest book house, and Yue study, which meet the diverse needs of readers.

In addition, the concept of space service has changed. The emergence of new 
library space means the change of library service concept, that is, the transition from "book-based" to "human-based". It reflects that the services of the library place the readers' needs at the highest level.

\subsection{Deficiencies in Space Service}

First, the service level of new space is low. Taking reader's research room as an example, some public libraries have higher requirements on the opening time and application process of reader's research room for easy management, which is not convenient for the reader.

Second, the construction of space service facilities is relatively backward. Although most public libraries have set up 24-hour self-service libraries, due to the shortage of funds and improper management, some libraries lack clear self-service guidance and instructions, and the number and types of self-service equipment in the library are insufficient. Therefore, it is necessary to strengthen the construction of space service facilities.

Thirdly, space service evaluation mechanism is deficient. At present, public libraries have not formed a unified evaluation standard of space service, which cannot effectively measure the quality and level of space service of public libraries. In addition, public libraries will investigate readers' opinions and needs before carrying out space services reconstruction, but they do not timely collect readers' feelings and suggestions after the reconstruction, which is not conducive to improving readers' satisfaction.

\section{Space Service Strategy of Public Libraries in China}

The development of public libraries in the future will put forward higher requirements for space service. Through the analysis of the current situation of space service of public libraries in East China, the following space service strategies are summarized.

\subsection{Strengthen the Librarian's Overall Quality and Improve Their Space Service Ability}

Library space service is a spatial extension of traditional services. With the diversification of space service types and the expansion of service scope, new space service will have higher requirements for librarians' professional quality. Librarians should not only possess professional information management knowledge, but also provide comprehensive and accurate consultation services for users. In addition, communication skills and psychological knowledge are necessary for librarians to actively communicate with users as well as constantly improve user satisfaction. The ways to improve librarians' professional skills include organizing learning and training, visiting and absorbing good experience and methods, and skills competition, etc. The librarians' accurate understanding and positioning of space service is conducive to giving full play to the advantages of space service. Hefei Library took the lead in carrying out the basic public service training of 
urban reading space to improve the basic professional skills and qualities of librarians.

\subsection{Promote the Development of Space Services Based on Information Technology}

The rapid development of information technology has prompted public libraries to launch a wave of building new library, which is more modern in space function and layout and can better reflect the characteristics of the times. The close combination of information technology and space service provides readers with intelligent, interactive and experience-based space service. Public libraries should first improve the infrastructure construction in libraries to ensure the basic needs of readers. For example, according to different users' needs, libraries should strengthen the construction of software and hardware facilities of each reading space, computers, projectors, whiteboards, office software, etc. While improving infrastructure construction, libraries should also increase investment in information systems and self-service equipment to improve the efficiency of space management.

\subsection{Strengthen Collaboration with Internal and External Institutions to Expand New Space for Space Services}

Faced with the diversified needs of readers, the space service that a single public library can provide is limited in the same region. Different types of libraries can enhance collaboration and realize space service reengineering from multiple aspects, such as adopting uniformity. The work \& management platform realizes technology sharing, and provides database resource sharing to other member libraries. In addition, public libraries should attach importance to collaboration with other external institutions. Public libraries can actively explore innovative and more distinctive library space service strategies, cooperate with government agencies, other cultural units, news media, publishing houses, database providers, enterprises and communities, and utilize the resources of these institutions to provide readers with a comprehensive library experience.

\subsection{Respect Users' Needs and Develop Evaluation Mechanism}

With the improvement of users' information literacy and the change of technological environment, the layout and service of traditional libraries cannot meet users' needs. Libraries are facing new development trends. Library space not only needs to be arranged around the collection of books, but also needs to be constructed with people as the core, to create more learning space, communication space and creative space for users. Only by understanding users' needs in various ways and letting users participate in library space services can library truly become the public cultural space and serve the region where it is located.

Library's space service is not accomplished overnight. It is a complete process consisting of space demand investigation, space planning, implementation plan- 
ning, feedback collection, overall evaluation and other steps. Establishing a reasonable evaluation mechanism can help public libraries fully understand user's feeling and feedback as well as find the deficiencies in the process of space service and take measures to rectify them in time.

\section{Conclusion}

This paper investigates the space services of 51 public libraries in East China and finds that there are still some problems in the space services of public libraries. Under the background of the new era, to provide users with satisfactory space service, it is necessary to strengthen the training of librarians' overall quality, improve librarians' space service ability, promote the development of space services based on information technology, strengthen collaboration with internal and external institutions to expand new service space and respect users' needs and develop evaluation mechanism.

\section{Acknowledgements}

Our team worked very hard during the investigation. We extend our deepest thanks to all those who have supported us a lot during the research.

\section{Conflicts of Interest}

The authors declare no conflicts of interest regarding the publication of this paper.

\section{References}

[1] Wu, J.Z. (2017) Re-Discussion of Ten Hot Topics in the Development of Librarianship. Journal of Library Science in China, 43, 4-17.

[2] Spencer, M. and Watstein, S. (2017) Academic library spaces: Advancing Student Success and Helping Students Thrive. Libraries and the Academy, 17, 389-402. https://doi.org/10.1353/pla.2017.0024

[3] Xiao, L. (2013) The Library Space Functionality and Spatial Layout Design in Post Digital Library Era. Library and Information Science, 57, 5-10.

[4] Zhang, W.L., Zhang, T. and Chen, H.L. (2018) Survey and Analysis on Space Distribution of Provincial Public Library in China. Information Research, 3, 89-94.

[5] Ma, C.H. (2019) On Hackerspace Service Mode of Academic Library in Transition Period. The Library Journal of Henan, 39, 58-60.

[6] Chen, J. (2018) Practice and Enlightenment from Services for Mobile Makers in San Jose Public Library. Library Science Research \& Work, 11, 69-72.

[7] Dong, G.Q. (2018) Study on Multi-Dimensional Space Service Design of University Libraries: A Case Study of Nanyang Technological University Library. Library Development, 6, 74-80.

[8] Zhao, Z.G. (2015) The Transformation and Development of New Library Space in the Information Age. Library World, 4, 4-7+21. 